\title{
Motivational Factors for Learning English as a Second Language Acquisition in Canada
}

\author{
Shahla Sattar Khan ${ }^{1} \&$ Mehmet Takkac ${ }^{1}$ \\ ${ }^{1}$ English Department, Ataturk University, Erzurum, Turkey \\ Correspondence: Shahla Sattar Khan, English Department, Atatürk Üniversitesi 25240 Erzurum, Turkey. Tel: \\ 90-442-231-1111. E-mail: sky_k7@ hotmail.com
}

Received: December 18, 2020

Accepted: January 29, $2021 \quad$ Online Published: February 14, 2021

doi:10.5539/hes.v11n1p160

URL: https://doi.org/10.5539/hes.v11n1p160

\begin{abstract}
New immigrants' arrival in any country indeed brings new challenges to settle in the country. Learning the language of a new country is one of the major hassles in settling and starting a new life. In Canada, new immigrants must learn English as a second language because English is an official language and is also used day to day in almost all provinces except for a few states where the French language is more acceptable compared to English. Learning English requires motivation and there are some barriers in learning. Thus, this study addresses these barriers and assesses what motivational factors are there for new immigrants to learn English. It was a cross-sectional quantitative study conducted at a poly-cultural center, and Canada from June-2018 to December-2018. A total of 325 participants who registered and gave consent were included in this study. The results showed that factor 1 (Desire for career and economic enhancement) is significantly associated with age groups $(\mathrm{P}=0.001)$, gender $(0.001)$, educational status $(\mathrm{P}=0.012)$, and time in Canada $(\mathrm{P}=0.027)$. Factor 2 (Desire to become a global citizen) is not significantly associated with all demographic data except for gender $(\mathrm{P}=0.027)$. Factor 3 (Desire to communicate and affiliate with foreigners) shows an association with all other demographic characteristics, except for gender $(\mathrm{P}=0.63)$, nationality $(\mathrm{P}=0.568)$, and educational status $(\mathrm{P}=0.091)$. In factor 4 (Desire for self-satisfaction), only educational status $(\mathrm{P}=0.046)$ has a significant association. Factor 5 (self-efficacy) and factor 6 (Desire to be integrated with other cultures) do not show any significant association with any demographic characteristics. In conclusion, the main motivating factors for new immigrants learning English as a second language acquisition is the desire for career and economic enhancement and the desire to communicate and affiliate with foreigners.
\end{abstract}

Keywords: motivation, barriers, English, learning, second language, acquisition

\section{Introduction}

\subsection{Introduction to the Problem}

English learning plays a vital role in settling in Canada as a new immigrant. This learning process is indeed affected by several motivational factors or barriers, which was already presented by a model described by Gardner (1982) almost four decades ago. This model depicted mainly four factors like social and cultural milieu; individuals are different, the context of learning, and its impact. Nevertheless, being an adult learner and based on andrology, new immigrants should have some inner motivation, it fulfils practical needs and it is connected to a real problem (Literacy \& Network, 2013). It was further recognized and emphasized by Gardner (1990), and stated that three elements are critical for learning a second language i.e., willingness, hard work, and a positive attitude toward it. Many studies (Othman et al., 2013; Waseem \& Jabeen, 2013; Viju, 2015) illustrated that motivational factors play a vital role in any second language acquisition (SLA).

Nevertheless, this is one of the requirements for all new immigrants to pass the English test, either IELTS or TOEFL, and it is supposed that while they arrive in Canada, they should be fluent in English. This is imposed only on principal applicants and does untruly apply to other family members and sponsored immigrants (Kilbride, et al.2008). Yet, new immigrants, even principal applicants, are not fluent in the English language and face many challenges during settlement in Canada initially. An official website illustrated that even a quarter of principal immigrants spoke neither English nor French, so the family members, sponsored parents, or refugee's status were worse (CIC Facts \& Figures, 2017). Consequently, family members and sponsored parents suffer more to face these challenges while settling down in Canada. However, principal applicants as the new immigrants go 
through the same hassles to settle in Canada.

\subsection{Importance of the Problem}

Language proficiency for new immigrants is critical because it has a significant impact on mental and physical well-being. Which of course, is necessary to reduce the stresses caused by challenges being faced by them, which encourage them to integrate into the new system easily and comfortably (Yaksuhko and Chronister, 2005). While taking care of the settlement of new immigrants, we should keep in mind that these new arrivals must pass through different stages of adaptation from euphoria, dissentient with frustration, gradual adjustment with a slow recovery, and acceptance (ISAN, 2019). The acquisition of a second language makes the scenario worse, and they become frustrated (Khan and Takkac, 2019). To cope with this situation, the prerequisite is to learn the English language and without motivation, it seems difficult to go for the acquisition of English as a second language.

\subsection{Relevant Scholarship}

Many studies are published so far, which describe how motivational factors work for the acquisition of English. Many researchers have emphasized who dealt with the second and foreign language learning that motivation is one of the main factors in the target language learning success (Rueda \& Chen, 2005). Our study is highlighting specifically the motivational factors for newcomers who want to learn English as a second language for the settlement in Canada. However, due to the diversity in the background of newcomers, their perspectives and motivation on learning English might differ from each other (Zusho \& Pintrich, 2003). In fact, the goal of becoming fluent English speakers is embraced by most newcomers who recognize that learning English is a fundamental requirement for acceptance and participation in an English dominant world. It is important to them; becoming English speaking is the same as becoming American. English is not just a vehicle for communication; it is a social and political marker of affiliation and belonging. How quickly, how well, and in what manner immigrants learn English has become the major public issue in the socialization of immigrant children in the United States (Oslen, 2000).

Nonetheless, there are not many pieces of research published, so far which directly assess the motivational factors for learning English as new immigrants, but some studies illustrated the importance of the motivational factors for learning English in different circumstances. For instance, a study conducted on Hungarian students describes the motivation for learning English as a foreign language in three distinct learner populations: secondary school pupils, university students, and adult language learners. The main factors affecting the student second language (L2) motivation were language-learning attitudes, and the Ideal L2 self, which provides empirical support for the main construct of the theory of the L2 Motivational Self-System (Dörnyei, 2009).

English in Taiwan, just like most countries in Asia, is treated as a subject for study rather than as a living language to be spoken in daily conversation. Therefore, the EFL classroom context is different from a natural ESL learning environment. The lack of a surrounding community of English speakers outside the classroom increases the challenge for EFL learners and for the instructors. Another important determinant of language learning achievement is the provocation (Othman et al., 2013; Waseem \& Jabeen, 2013; Viju, 2015)). These studies have claimed that there is a positive relationship between the learning environment and student motivation, stating that a good learning environment helps improve the learning outcomes, indeed inspires and boosts the learning spirit. Another similar kind of empirical study, using a quantitative methodology, explored the perceptions of students at a Taiwanese technical university concerning its EFL learning environment in three aspects: the physical environment, instructional arrangements, and social interaction. The study also examined the relationship between the learning context and student motivation. Quantitative data revealed that the EFL environment in the three aspects was considered by students to be an obstacle to their learning and that student motivation positively correlated with the learning environment ( $\mathrm{Wu}$ and $\mathrm{Wu}, 2008$ ).

Another study investigated how Japanese elementary school pupils' intrinsic and extrinsic motivation for learning English changed with age (174 third and 171 sixth graders). Factor analysis identified five underlying factors: interest in foreign countries, intrinsic motivation, caregivers' encouragement, instrumental motivation, and anxiety. The results showed significant differences in intrinsic motivation, interest in foreign countries, and instrumental motivation between the third and sixth graders. The third graders' mean scores were higher than those of the sixth graders. This study revealed a rather steady developmental decline in intrinsic and extrinsic motivation for learning English, which might be attributed to general development trends in contemporary Japanese elementary school pupils (Carreira, 2006). 
In a study, a group of Japanese and Chinese high school students was examined and compared regarding their motivation to learn English. Although Japanese students expressed a strong interest in English as a subject, they displayed a weaker interest in intrinsic motivation and a stronger one for extrinsic motivation compared to junior high school students. Nevertheless, Japanese students who achieved better scores were not only zealous to achieve better scores but also were much more interested in English as a language, the culture, and people. Chinese high school students' motivation did not vary dramatically from their junior high school peers. They were also more pragmatically oriented toward the study of English, i.e., they thought English would be valuable and necessary for their future. Even if they do well, they believe they can do better with more effort to be successful in the future (Tachibana, 1996).

Student motivation may have significant influence on essential academic outcomes. However, students' motivation may decline, as they grow older, which Young (2011) examined in a study conducted on six motivation constructs (self-efficacy, interest, mastery goal orientation, engagement, avoidance coping, and effort withdrawal) of a large group of students from 78 schools in Singapore in learning English. The results showed that are, (a) the scores for self-efficacy, interest, mastery goal orientation, and engagement tended to be lower whereas avoidance coping and effort withdrawal tended to be higher for the secondary students, (b) boys tended to have lower scores, and (c) the gap in motivation between primary and secondary tended to be greater for girls. Since motivation may have important influences on subsequent learning outcomes, we should seriously consider the implications of these grades- and gender-related patterns and pay attention particularly to boys in primary schools and girls in secondary schools.

Al-Tamimi, and Shuib (2009) through a questionnaire and interviews collected data to assess the motivation of the students. The findings of the study have suggested that there are many instrumental reasons for learning the English language, including utilitarian and academic reasons. The students also regarded personal reasons as important motives. However, regarding the integrative reasons, the results provided evidence that learning English as a part of the culture of its people had the least impact on students' English language motivation. Alternatively, data for the students' attitudes revealed that most students had positive attitudes toward the social value and educational status of English. Besides, the findings showed the students' positive orientation toward the English language. Interestingly enough, the results indicated that a high number of students showed their interest in the culture of the English-speaking world as represented by English-language films. Finally, some pedagogical implications that would help tap the students' motivation and attitudes were presented.

\subsection{Hypothesis}

As mentioned earlier by many studies (Gardner, 1985 \& 1990; Othman et al., 2013; Waseem \& Jabeen, 2013; Viju, 2015) that motivational factors are important for the acquisition of English as a second language. Therefore, the hypothesis is that new immigrants must have motivational factors for learning English as well as there are some barriers too for their learning. Based on this hypothesis, we are looking for answers to the following research questions:

- What motivational factors are motivating new immigrants to the acquisition of English as a second language?

- What barriers do new immigrants face during the acquisition of English as a second language?

\section{Method}

\subsection{Participants (Subjects) Characteristics}

All male and female adult new immigrants only last two years who are registered at polyculture center, Mississauga, Ontario, Canada for learning English. They belonged to many countries from Europe to Asia and registered for learning English at the center.

\subsection{Sampling Procedure}

Initially, all 475 registered at polyculture centers, Mississauga, Ontario, Canada new immigrants were included during the period of June-2018 to December-2018. A convenient sampling technique was applied and included all. However, due to exclusion criteria, children under 18 years and elderly more than 60 years of age were excluded.

\subsubsection{Sample Size, Power, and Precision}

A convenient sampling technique was applied and included initially 475 registered new immigrants, after the exclusion of 75 (19\%) from the total, only 400 participants have participated in the study. The calculated power was nearly $90 \%$ and due to a good sample size, the study revealed a high precision. 


\subsubsection{Measures and Covariates}

The study mainly focused on assessing the motivational factors and barriers for the acquisition of English as a second language during the settlement of new immigrants. A validated and reliable questionnaire was adopted and added some variables relevant to sociodemographic information. After the addition of the variables, a pilot study was run on 20 participants who were not part of the sample selected for the actual study. The pilot study showed a reliability coefficient i.e., 0.70. The questionnaire is based on a validated instrument "The Foreign Language Learning Motivation Questionnaire (FLLMQ-6), which has been applied for collecting data (Gonzales \& Lopez, 2016). The factors that comprise FLLMQ-6 are the desire for career and economic enhancement, desire to be global citizens, desire to communicate and affiliate with foreigners, desire for self-satisfaction in learning, self-efficacy, and desire for cultural integration. The questionnaire consists of 50-Lickert items that coincide with the six factors identified. Usually, educational studies are considered low-risk studies concerning human participation (Sullivan, 2011). This study involved human subjects only for taking their opinion and no experiment was done in terms of having any effect on the human body. However, an ethical (BERA, 2011) approval has been taken from the university for this educational study.

\subsubsection{Research Design}

It was a quantitative and analytical, cross-sectional study design since we have collected data based on a validated and reliable questionnaire (Gonzales \& Lopez, 2016) during a period whenever participants feel convenient.

\section{Results}

\subsection{Recruitment}

The recruitment in the study started with the contact of all registered at the polyculture center, Mississauga, Ontario, Canada. This center usually registers new immigrants and facilitates them for settlement in Canada. A total of 475 were included in the study and contacted to get consent for participation in the study. However, finally only 310 were left after applying exclusion criteria to participate in the study. It was done during June-2018 to December-2018.

\subsection{Statistics \& Data Analysis}

The collected data were cleaned and fed into an SPSS - IBM version 21 software with the help of a statistician. The first deceptive analysis statistical calculations were done for getting a holistic picture of the data. The mean value $(+95 \% \mathrm{CI})$ of the participants' reactions on the Likert scale was determined and the correlation of their reactions with socio-demographic variables was assessed. Later, chi-square was applied for assessing any significant association among different variables. A p-value equal to or less than 0.05 was considered a significant level for assuring any association.

\subsection{Baseline Data}

We approached 400 participants after exclusion criteria; however, 75 immigrants left the center for their reason. Thus, out of 325 , only 310 (95\%) have given consent for participation; therefore, the response rate is reasonable for starting the study. We have approached almost 325 immigrants; however, 310 have given consent for participation so the response rate is about $95 \%$. Table 1 shows that the majority (44.5\%) belonged to an age group of 41-50 years for a mean value of 40 ( \pm 9.932$)$. Demographic characteristics show that two-thirds $(66.8 \%)$ were females. In the group most immigrants came from Asian countries (43\%), followed by the Middle East (35\%) and other countries. Almost one-third of the participant has a master's degree (38\%), followed by a Ph.D. (20\%). As regards the native language, 35\% were speaking Arabic, $20 \%$ were Urdu speakers, $12 \%$ were Hindi-speaking and only $6 \%$ were English speakers. Regarding the duration in Canada, $37 \%$ lived here for more than a year, 30\% lived in Canada for around 6 to 9 months, while 25\% lived in Canada for 3 to 6 months (Table $1)$. 
Table 1. Demographic characteristics of the participants $(n=310)$

\begin{tabular}{llll}
\hline Characteristics & & Frequency & Percent \\
\hline Age groups & 20-30 years & 50 & 16.1 \\
$\mathbf{( 4 0 \pm 9 . 9 3 2 )}$ & 31-40 years & 104 & 33.5 \\
& 41-50 years & 138 & 44.5 \\
Gender & 50-60 years & 18 & 5.8 \\
& Male & 103 & 33.2 \\
Nationality & Female & 207 & 66.8 \\
& Asian & 134 & 43.2 \\
& Middle East & 109 & 35.2 \\
& African & 48 & 15.5 \\
Education Status & European & 12 & 3.9 \\
& Australian & 7 & 2.3 \\
& Higher Secondary & 60 & 19.4 \\
& Graduation & 69 & 22.3 \\
Native Language & Master & 117 & 37.7 \\
& PhD & 64 & 20.6 \\
& Arabic & 109 & 35.2 \\
& Urdu & 62 & 20.0 \\
& Hindi & 38 & 12.3 \\
& Chinese & 29 & 9.4 \\
& English & 18 & 5.8 \\
Total Time in Canada & Others & 54 & 17.4 \\
& $<3$ months & 20 & 6.5 \\
& 3-6 months & 79 & 25.5 \\
& 6-9 months & 95 & 30.6 \\
& $>1$ year & 116 & 37.4 \\
\hline
\end{tabular}

\subsection{Inferential Data}

There are mainly 6-factors as a group, which are considered motivational factors for foreign language learning. Under each factor, there are many statements and table 2 shows the frequency and percentages of the responses of the statements. In factor 1, out of six statements, for three statements such as they are interested in learning English to improve the chance of getting a good job (93.3\%), to get a high paying job (93.3\%), as a foreign language (FL) proficiency will have financial benefits for me (93.3\%), and for training in my future job (93.3\%) strongly agreed. The statements of 2 nd factor are mainly related to the understanding of the culture and it also illustrates similar results, for instance almost for statements each participant strongly agreed or agreed that the learning of English as a foreign language is essential for the understanding of the culture. In fact, for factor 3, which is relevant to communication with foreigners, all have shown agreement for all statements, except one who is learning English as a foreign language. It is useful when I travel abroad, for which the majority (91\%) were neutral. Similar results have been shown for factors 4,5 and 6 . Table 3 depicts the descriptive analysis of the six motivational factors after combining all statements and then analysing.

Table (4) shows the association among the six motivational factors and after analysing the results and illustrates the p-value. A p-value of less than 0.05 was considered a significant level for assessing any association. Factor 1(Desire for career and economic enhancement) is significantly associated with age groups $(\mathrm{P}=0.001)$, gender (0.001), educational status $(\mathrm{P}=0.012)$, and time in Canada $(\mathrm{P}=0.027)$. Factor 2 (Desire to become a global citizen) is not significantly associated with all demographic data, except for gender $(\mathrm{P}=0.027)$. Factor 3 (Desire to communicate and affiliate with foreigners) shows an association with all other demographic characteristics, except gender $(\mathrm{P}=0.63)$, nationality $(\mathrm{P}=0.568)$, and educational status $(\mathrm{P}=0.091)$. In factor 4 (Desire for self-satisfaction), only educational status $(\mathrm{P}=0.046)$ has a significant association with educational status. Factor 5 (self-efficacy) and factor 6 (Desire to be integrated with other cultures) do not show any significant association with any demographic characteristics. 
Table 2. Responses on Foreign Language Learning Motivation Questionnaire

\begin{tabular}{|c|c|c|c|c|c|c|c|}
\hline \multicolumn{2}{|c|}{ Item (abridged) } & SA $(\%)$ & $\mathrm{A}(\%)$ & $\mathbf{N}(\%)$ & DA (\%) & SDA $(\%)$ & Mean (SD) \\
\hline \multicolumn{8}{|c|}{ Factor 1: Desire for career and economic enhancement } \\
\hline 1. & ...to improve my chances of getting a good job. & 296(93.3) & $0(0)$ & $10(3.2)$ & $03(1.0)$ & $01(0.3$ & $4.89( \pm 0.5)$ \\
\hline 2. & ...to get a high paying job. & 291(93.3) & $0(0)$ & $11(3.5)$ & $06(1.9)$ & $01(0.3$ & $4.86( \pm 0.6)$ \\
\hline 3. & ...FL proficiency will have financial benefits for me. & 292(93.6) & $0(0)$ & $12(3.8)$ & $04(1.3)$ & $01(0.3$ & $4.87( \pm 0.5)$ \\
\hline 4. & ...for training in my future job. & 291(93.3) & $0(0)$ & $14(4.5)$ & $03(1.0)$ & $01(0.3$ & $4.87( \pm 0.5)$ \\
\hline 5. & ...have better job opportunities after graduation. & $06(1.9)$ & $04(1.3)$ & 285(91.3) & $14(4.5)$ & $01(0.3$ & $3.00( \pm 0.3)$ \\
\hline 6. & ...FL gives me more opportunities after graduation. & $06(1.9)$ & $04(1.3)$ & 285(91.3) & $14(4.5)$ & $01(0.3$ & $3.00( \pm 0.3)$ \\
\hline 7. & ...FL gives me an edge over other applicants for a job. & $06(1.9)$ & $04(1.3)$ & 285(91.3) & $14(4.5)$ & $01(0.3$ & $3.00( \pm 0.3)$ \\
\hline 8. & ...FL is another way of enriching me for my future career. & 296(94.9) & $0(0)$ & $10(3.2)$ & $03(1.0)$ & $01(0.3$ & $4.89( \pm 0.5)$ \\
\hline \multicolumn{8}{|c|}{ Factor 2: Desire to become global citizen } \\
\hline 9. & ...FL allows me to understand other cultures. & $219(70.2)$ & $91(29.2)$ & $0(0)$ & $0(0)$ & $0(0)$ & $4.71( \pm 0.4)$ \\
\hline 10. & ...FL is one way of learning another culture. & $185(59.3)$ & $125(40.1)$ & $0(0)$ & $0(0)$ & $0(0)$ & $4.60( \pm 0.4)$ \\
\hline 11. & ...FL broadens my view of other cultures. & $173(55.0)$ & 137(43.9) & $0(0)$ & $0(0)$ & $0(0)$ & $4.56( \pm 0.4)$ \\
\hline 12. & ...can appreciate more foreign people if I know their language. & 205(65.7) & $105(33.7)$ & $0(0)$ & $0(0)$ & $0(0)$ & $4.66( \pm 0.4)$ \\
\hline 13. & ...FL will allow me to understand other cultures. & $230(73.7)$ & $80(25.6)$ & $0(0)$ & $0(0)$ & $0(0)$ & $4.74( \pm 0.4)$ \\
\hline 14. & ...FL is important for me to understand other cultures. & $210(67.3)$ & $100(32.1)$ & $0(0)$ & $0(0)$ & $0(0)$ & $4.68( \pm 0.4)$ \\
\hline 15 . & ...FL gives me self-confidence to understand other cultures. & $196(62.8)$ & $114(36.5)$ & $0(0)$ & $0(0)$ & $0(0)$ & $4.63( \pm 0.4)$ \\
\hline 16. & ...to be more educated about other cultures. & $196(62.8)$ & $114(36.5)$ & $0(0)$ & $0(0)$ & $0(0)$ & $4.63( \pm 0.4)$ \\
\hline \multicolumn{8}{|c|}{ Factor 3: Desire to communicate and affiliate with foreigners } \\
\hline 17. & ...to communicate with foreigners in their native language. & 249(79.8) & $53(17.0)$ & $0(0)$ & $0(0)$ & $8(2.6)$ & $4.83( \pm 0.3)$ \\
\hline 18. & ...to speak to foreigners using their own language. & 251(80.4) & $53(17.0)$ & $2(0.6)$ & $1(0.3)$ & $2(0.6)$ & $4.83( \pm 0.3)$ \\
\hline 19. & ...it is easier for me to relate with foreigners. & 254(81.4) & $53(17.0)$ & $3(1.0)$ & $0(0)$ & $0(0)$ & $4.83( \pm 0.3)$ \\
\hline 20. & ...I am fascinated when I hear a foreigner speaking & 251(80.4) & $53(17.0)$ & $0(0)$ & $3(1.0)$ & $3(1.0)$ & $4.83( \pm 0.3)$ \\
\hline 21. & ...to go to the country where it is spoken. & $256(82.1)$ & $52(16.7)$ & $0(0)$ & $2(0.6)$ & $0(0)$ & $4.83( \pm 0.3)$ \\
\hline 22. & ...it is useful when I travel abroad. & $06(1.9)$ & $04(1.3)$ & 285(91.3) & $14(4.5)$ & $1(0.3)$ & $3.00( \pm 0.3)$ \\
\hline \multicolumn{8}{|c|}{ Factor 4: Desire for self-satisfaction } \\
\hline 23. & $\begin{array}{l}\text {...enjoy learning an FL when my friend gives me } \\
\text { some books on FL. }\end{array}$ & 184(59.0) & $105(33.7)$ & $07(2.2)$ & $07(2.2)$ & $07(2.2)$ & $4.63( \pm 0.3)$ \\
\hline 24. & ..enjoy browsing websites that deal with FL on the Internet. & 189(60.6) & 108(34.6) & $03(1.0)$ & 06(1.9) & $04(1.3)$ & $4.63( \pm 0.4)$ \\
\hline 25. & $\begin{array}{l}\text {... like learning an FL because I have friends who } \\
\text { have enjoyed studying it. }\end{array}$ & $188(60.3)$ & $108(34.6)$ & $0(0)$ & $11(3.5)$ & $03(1.0)$ & $4.63( \pm 0.4)$ \\
\hline 26. & $\begin{array}{l}\text {...enjoy watching movies on TVs and DVD specially } \\
\text { if they are in an FL. }\end{array}$ & 194(62.2) & 111(35.6) & $01(0.3)$ & $04(1.3)$ & $0(0)$ & $4.63( \pm 0.4)$ \\
\hline 27. & ...my classmates are having a good time learning with me. & 192(61.5) & $113(36.2)$ & $02(0.6)$ & $03(1.0)$ & $0(0)$ & $4.63( \pm 0.4)$ \\
\hline 28. & ...enjoy learning an FL in order to pass an entrance examination. & 193(61.9) & $114(36.5)$ & $03(1.0)$ & $0(0)$ & $0(0)$ & $4.63( \pm 0.4)$ \\
\hline \multicolumn{8}{|c|}{ Factor 5: Self-Efficacy } \\
\hline 29. & ...can relate well in my FL class. & $194(62.2)$ & $114(36.5)$ & $01(0.3)$ & $01(0.3)$ & $0(0)$ & $4.63( \pm 0.4)$ \\
\hline 30. & ...enjoy learning an FL because I feel I am good at it. & $195(62.5)$ & $113(36.2)$ & $02(0.6)$ & $0(0)$ & $0(0)$ & $4.63( \pm 0.4)$ \\
\hline 31. & ...feel comfortable speaking in my FL classes. & $175(56.1)$ & 101(32.4) & $13(4.2)$ & $12(3.8)$ & $09(2.9)$ & $4.63( \pm 0.4)$ \\
\hline 32. & ...enjoying learning an FL even if it is difficult. & $186(59.6)$ & $113(36.2)$ & $02(0.6)$ & $06(1.9)$ & $03(1.0)$ & $4.63( \pm 0.3)$ \\
\hline 33. & $\begin{array}{l}\text {... delighted when my teacher notices how I am } \\
\text { progressing in my FL class. }\end{array}$ & 172(55.1) & 103(33.0) & $06(1.9)$ & $18(5.8)$ & $010(3.2)$ & $4.63( \pm 0.4)$ \\
\hline 34. & ...believe I have the ability in learning it. & $182(58.3)$ & 104(33.3) & $07(2.2)$ & $11(3.5)$ & $06(1.9)$ & $4.63( \pm 0.3)$ \\
\hline \multicolumn{8}{|c|}{ Factor 6: Desire to be integrated with other cultures } \\
\hline 35 . & ...to live in foreign land that is why I am learning an FL. & 190(60.9) & $105(33.7)$ & $06(1.9)$ & $06(1.9)$ & $03(1.0)$ & $4.63( \pm 0.4)$ \\
\hline 36. & ...to be able to interact with foreigners well. & 192(61.5) & $108(34.6)$ & $03(1.0)$ & $05(1.6)$ & $02(0.6)$ & $4.63( \pm 0.4)$ \\
\hline 37. & ...because I am also interested in foreign cultures. & 185(59.3) & $110(35.3)$ & $07(2.2)$ & $06(1.9)$ & $02(0.6)$ & $4.63( \pm 0.2)$ \\
\hline 38. & ...FL will prepare me to live in foreign country. & $184(59.0)$ & $113(36.2)$ & $02(0.6)$ & $08(2.6)$ & $03(1.0)$ & $4.63( \pm 0.4)$ \\
\hline 39. & ...to live with another culture that is why I am studying an FL. & $187(59.9)$ & $108(34.6)$ & $06(1.9)$ & $07(2.2)$ & $02(0.6)$ & $4.63( \pm 0.4)$ \\
\hline 40. & ...to be able to socialize with foreigners. & $196(62.8)$ & $114(36.5)$ & $0(0)$ & $0(0)$ & $0(0)$ & $4.63( \pm 0.4)$ \\
\hline
\end{tabular}

$\mathrm{SA}=$ Strongly Agree, $\mathrm{A}=$ Agree, $\mathrm{N}=$ Neutral, $\mathrm{DA}=$ Disagree, $\mathrm{SDA}=$ Strongly Disagree 
Table 3. Descriptive analysis of 6 - motivational factors for Foreign Language Learning

\begin{tabular}{lccccc}
\hline Motivational Factors & Mean & SD & Median & \multicolumn{2}{c}{ 95\% CI } \\
\cline { 4 - 6 } & & & & Upper & Lower \\
\hline Factor 1: Desire for career and economic enhancement & 33.39 & 2.872 & 34.00 & 33.07 & 33.71 \\
Factor 2: Desire to become global citizen & 37.12 & 2.575 & 37.00 & 36.83 & 37.41 \\
Factor 3: Desire to communicate and affiliate with foreigners & 26.88 & 2.063 & 28.00 & 26.65 & 27.11 \\
Factor 4: Desire for self-satisfaction & 27.29 & 3.095 & 30.00 & 26.93 & 27.63 \\
Factor 5: Self-Efficacy & 26.91 & 3.177 & 27.00 & 26.55 & 27.26 \\
Factor 6: Desire to be integrated with other cultures & 27.26 & 3.091 & 30.00 & 26.90 & 27.60 \\
\hline
\end{tabular}

Table 4. Association of 6 - motivational factors for demographic data

\begin{tabular}{|c|c|c|c|c|c|c|}
\hline Motivational Factors & $\begin{array}{l}\text { Age } \\
\text { groups }\end{array}$ & Gender & Nationality & $\begin{array}{l}\text { Educational } \\
\text { Status }\end{array}$ & $\begin{array}{l}\text { Native } \\
\text { language }\end{array}$ & $\begin{array}{l}\text { Time in } \\
\text { Canada }\end{array}$ \\
\hline Factor 1: Desire for career and economic enhancement & $\mathrm{P}=0.001$ & $\mathrm{P}=0.001$ & $\mathrm{P}=0.816$ & $\mathrm{P}=0.012$ & $\mathrm{P}=0.264$ & $\mathrm{P}=0.027$ \\
\hline Factor 2: Desire to bec & $\mathrm{P}=0.244$ & $\mathrm{P}=0.027$ & 52 & 34 & 1 & $=0.182$ \\
\hline Factor 3: Desire to communicate and affiliate & $\mathrm{P}=0.001$ & $\mathrm{P}=0.631$ & $\mathrm{P}=0.568$ & $\mathrm{P}=0.091$ & $\mathrm{P}=0.012$ & $\mathrm{P}=0.013$ \\
\hline Factor 4: Desire for self-satisfaction & $\mathrm{P}=0.492$ & $\mathrm{P}=0$. & $\mathrm{P}=0.331$ & $\mathrm{P}=0.046$ & $\mathrm{P}=0.581$ & $=0.951$ \\
\hline Fact & & & & & & 91 \\
\hline Factor 6: Desire to be integrated with other cultures & $\mathrm{P}=0.478$ & $\mathrm{P}=0.669$ & $\mathrm{P}=0.838$ & $\mathrm{P}=0.608$ & $\mathrm{P}=0.245$ & $\mathrm{P}=0.742$ \\
\hline
\end{tabular}

\section{Discussion}

Foreign language learning seems difficult until there are some motivational factors, which motivate the learner to learn any foreign language (FL) including English. Adult learning is predicated on some experiential learning cycle (Arkoful and Abiadoo, 2015) that is relevant to four learning principles such as it should be concrete experience, reflective observation of new experience, abstract conceptualization, and active experimentation. However, adults learn more quickly if this learning has some motivational factors, which are relevant to their day-to-day active experience and outcome (Kolb, 2005). A study shows that overall there is an essential role of all six motivational factors for learning English as a foreign language. Authors (Khan and Takkac, 2019) did a previous study also depicted that that immigrant had an optimistic approach to learning English as a second language. However, they face some challenges in learning English as well as integrating into Canadian culture. In this study, the response rate was excellent; however, most participants were females. Many demographic characteristics affect meaning; however, gender also plays an important role (Oxford, 1990). This high rate of responses from females endorsed females usually take all tasks seriously and try doing them with full commitment (Smith, 2008). The majority (44.5\%) belonged to the middle age group (41-50 years). It reflects a general immigrant population that usually achieves immigration in Canada (CIC, 2017). Many nationalities have participated in the study, however, Asians, Arab speakers from the Middle East mainly participated, and as this is a high number in Canada as new immigrants (CIC, 2017). I look at their educational status, a few of the sampled populations had completed a master's degree and a handful of participants had Ph.D. Hence, it is important to know the role of educational status for settling new immigrants in Canada and learning a foreign language, which should be helpful (Oxford, 1990; Khan and Takkac, 2019). Indeed, if the time span in Canada is increased, there will be more chances to settle easily as new immigrants and learn English as a foreign language (Lambart, 1973).

Learning English is a complicated phenomenon especially for those who never experience learning English as a foreign language (FL). It is multifactorial and depends upon many motivational factors. The factors include; cultural beliefs and expectations, educational policies, local influences, task requirements, personal preferences, learning opportunities, individual age, gender, educational level, and social class (Oxford, 1989; Oxford, 1990; Chamot \& Kupper, 1989). However, motivation is crucial, pivotal, and top of all factors. Motivation is multifaceted and it's not only a unitary concept (Oxford \& Shearin, 1996; Domyei, 2001a, 2001b). Fortunately, Robert Garner (1985, p.10) with his colleagues has initiated a study in Canada and started research on language learning motivation. Later the Gardner (1985, p.10) separately defines the second language motivation as "the extent to which individual works or strives to learn the language because of a desire to do so and the satisfaction experienced in this activity". The statement of Domyei (1998) is that in the absence of sufficient motivation, even individuals with abilities can hardly achieve long-term support.

Our study displays the association between the six motivational factors and analyses the results. The first three factors are mainly related to extrinsic motivation (Gardner, 1990) like personal development and become a global citizen. For example, factor 1(Desire for career and economic enhancement) is significantly associated 
with age groups, gender, educational status, and time spent in Canada. This is so noticeable that the first challenge for the immigrants is to settle down in the new country and to get a job moreover, to maintain their socioeconomic status. Therefore, all gender or different age groups must be motivated to learn English to fulfil the prerequisite to get a job in Canada. Similar findings are seen in the Wong study (2008) and indicate that there is no general trend for different age groups as different age groups have different mean motivation scores for learning English. There are many other motivational factors like factor 2 (Desire to become a global citizen) that is also not significantly associated with all demographic data, except for gender. Gender usually plays a significant role in motivation for second language learning and this difference has a significant impact on the learner's performance. The study proved that females have higher integrative motivation toward learning English than male students. (Narayanan, Rajasekaran \& Iyyappan, 2007). Factor 3 (Desire to communicate and affiliate with foreigners) shows an association with all other demographic characteristics, except gender, nationality, and educational status. A study reported (Hummel, 2013) that the major motivation to learn another language is to develop a communicative relationship with people from another culture.

The remaining factors are more related to intrinsic motivation (Gardner, 1990) such as self-satisfaction, self-efficacy, and integration with cultures. For instance, in factor 4 (Desire for self-satisfaction), only educational status $(\mathrm{P}=0.046)$ has a significant association with educational status. The evidence shows that the initiatives taken to promote self-fulfilment and self-satisfaction throughout the lifespan have a positive impact on individuals and communities (Donlevy, van Driel \& Hoareau, 2019). Factor 5 (self-efficacy) is self-efficacy and motivation to learn English as a second language. Self-efficacy plays a crucial role in learning as some studies (Raoofi, Tan \& Chan, 2012; Wang \& Pape, 2012) illustrated that self-efficacy is a strong predictor of performance in different language skills and tasks. Factor 6 (Desire to be integrated with other cultures) does not show any significant association with any demographic characteristics. Though no association found with any demographic characteristics, however, without differentiation of any age or gender or even qualification, all who arrive in a new country as immigrants should learn the local language and their ability to communicate effectively is crucial for their integration (Ager \& Strang, 2008; Gerstle, 2010). Nonetheless, the study demonstrated that either six factors related to intrinsic or extrinsic factors played a part in motivation for learning English, yet, for some factors gender and others for educational status contribute to motivational factors.

This study represented many significant findings for assessing the motivational factors for learning English as a second language. We have applied the "Foreign Language Learning Motivation Questionnaire (FLLMQ-6) for collecting data (Gonzales \& Lopez, 2016), which has not been used before for a specific group of new immigrants in Canada. However, the data were collected from only one poly-cultural center and the sample size might not be enough to generalize the results in all parts of Canada. Thus, I recommended that a similar kind of study should be conducted on a large-scale at multi-poly-cultural centers.

\section{Acknowledgments}

Cordial thanks to my supervisor Prof. Mehmet Takkac, who has always been an inspiration for me throughout my $\mathrm{PhD}$ program. I also appreciate Dr. Khan for helping in compiling, feeding and statistical analysis of the data.

\section{References}

Ager, A., \& Strang, A. (2008). Understanding integration: A conceptual framework. Journal of Refugee Studies, 21, 166-191. https://doi.org/10.1093/jrs/fen016

Arkorful, V., \& Abaidoo, N. (2015). The role of e learning, and advantages and disadvantages of its adoption in higher education. International Journal of Instructional Technology and Distance Learning, 12(1), 29-42.

Carreira, J. M. (2006). Motivation for learning English as a foreign language in Japanese elementary schools. Jalt journal, 28(2), 135. https://doi.org/10.37546/JALTJJ28.2-2

Chamot, A. U., \& Kupper, L. (1989). Learning Strategies in Foreign Language Instruction. Foreign Language Annals, 22(1), 13-22. https://doi.org/10.1111/j.1944-9720.1989.tb03138.x

CIC Facts and Figures. (2017). Immigration overview: Permanent Residents. Retrieved from https://open.canada.ca/data/en/dataset/082f05ba-e333-4132-ba42-72828d95200b

Donlevy, V., van Driel, B., \& Hoareau McGrath, C. (2019). Education as self-fulfillment and self-satisfaction (No. 2019/06). JRC Working Papers Series on Labor, Education and Technology.

Dörnyei, Z. (2001a). Motivational strategies in the language classroom. Cambridge, UK: Cambridge University Press. https://doi.org/10.1017/CBO9780511667343

Dörnyei, Z. (2001b). Teaching and researching motivation. Essex, England: Pearson Education Limited. 
Dörnyei, Z. (2009). The L2 motivational self-system. Motivation, language identity and the L2 self, 36(3), 9-11. https://doi.org/10.21832/9781847691293-003

Gardner, R. C. (1982). Language attitudes and language learning. In E. B. Ryan, \& H. Giles (Eds.), Attitudes towards language variation (pp. 132-147). Edward Arnold.

Gardner, R. C. (1985). Social psychology and second language learning: The role of attitudes and motivation. Edward Arnold, London.

Gardner, R. C. (1990). Attitudes, motivation and personality as predictors of success in foreign language learning. In T. S. Parry, \& C. W. Stansfield (Eds.). Language Aptitude Reconsidered. Englewood Cliffs, N. J.: Prentice-Hall.

Gonzales, R. D., \& Lopez, M. Y. (2016). Foreign Language Learning Motivation Questionnaire: Further Examination of a Six-Factor Model. Unpublished manuscript, Graduate School, University of Santo Tomas, Manila, Philippines.

Hummel, K. M. (2013). Target-language community involvement: Second-language linguistic self-confidence and other perceived benefits. Canadian Modern Language Review, 69, 65-90. https://doi.org/10.3138/cmlr.1152

ISAN. (2019). Get settled. Mental Health \& Wellness.

Khan, S. S., \& Takkac, M. (2019). Perception of Newcomers Regarding Learning English and Culture in Canada. English Language Teaching, 12(10), 86-95. https://doi.org/10.5539/elt.v12n10p86

Kilbride, K. M., Tyyska, V., Berman, R., Ali, M., Woungang, I., Guruge, S., Edwards, S., \& Cazzola, R. (2008). Reclaiming voice: Challenges and opportunities for immigrant women learning English. CERIS Working Paper Series, 2009, 72.

Kolb, A., \& Kolb, D. (2005). Learning Styles and Learning spaces: Enhancing experiential learning in higher education. Academy of management learning \& education, 4(2), 193-212. https://doi.org/10.5465/amle.2005.17268566

Kormos, J., \& Csizér, K. (2008). Age-related differences in the motivation of learning English as a foreign language: Attitudes, selves, and motivated learning behavior. Language learning, 58(2), 327-355. https://doi.org/10.1111/j.1467-9922.2008.00443.x

Lambert, W. E. (1973). Culture and Language as Factors in Learning and Education.

Literacy, C., \& Network, L. (2013). Principles of Adult Learning. Retrieved from http://www.literacy.ca/professional-development-2/principles-of-adultlearning

Narayanan, R., Rajasekaran Nair, N., \& Iyyappan, S. (2007). Do Female Students Have Higher Motivation than Male Students in Learning of English at the Tertiary Level?.

Olsen, L. (2000). Learning English and learning America: Immigrants in the center of a storm. Theory into practice, 39(4), 196-202. https://doi.org/10.1207/s15430421tip3904_2

Othman, F. H., \& Shuqair, K. M. (2013). The Impact of Motivation on English Language Learning in the Gulf States. International Journal of Higher Education, 2(4), 123. https://doi.org/10.5430/ijhe.v2n4p123

Oxford, R. (1990). Language Learning Strategies (3rd ed.). New York.

Oxford, R. L., \& Shearin, J. (1996). Language learning motivation in a new key. In R. L. Oxford (Ed.), Language learning motivation: Pathways to the new century (pp. 155-187).

Oxford, R., \& Crookall, D. (1989). Research on Language Learning Strategies: Methods, Findings and Instructional Issues. The Modern Language Journal, 73(4), 404-419. https://doi.org/10.1111/j.1540-4781.1989.tb05321.x

Raoofi, S., Tan, B. H., \& Chan, S. H. (2012). Self-Efficacy in Second/Foreign Language Learning Contexts. English Language Teaching, 5(11), 60-73. https://doi.org/10.5539/elt.v5n11p60

Rueda, R., \& Chen, C. Y. B. (2005). Assessing motivational factors in foreign language learning: Cultural variation in key constructs. Educational Assessment, 10(3), 209-229. https://doi.org/10.1207/s15326977ea1003_4

Simich, L., Beiser, M., Stewart, M., \& Mwakarimba, E. (2005). Providing Social Support for Immigrants and Refugees in Canada: Challenges and Directions. Journal of Immigrant and Minority Health, 7(4), 259-268. 
https://doi.org/10.1007/s10903-005-5123-1

Smith, G. (2008). Does gender influence online survey participation?: A record-linkage analysis of university faculty online survey response behavior. ERIC Document Reproduction Service No. ED 501717.

Sullivan, G. M. (2011). Education research and human subject protection: crossing the IRB quagmire. https://doi.org/10.4300/JGME-D-11-00004.1

Tachibana, Y., Matsukawa, R., \& Zhong, Q. X. (1996). Attitudes and motivation for learning English: A cross-national comparison of Japanese and Chinese high school students. Psychological reports, 79(2), 691-700. https://doi.org/10.2466/pr0.1996.79.2.691

Tamimi, A., \& Shuib, M. (2009). Motivation and attitudes towards learning English: A study of petroleum engineering undergraduates at Hadhramout University of Sciences and Technology. GEMA Online ${ }^{\circledR}$ Journal of Language Studies, 9(2).

The british Educational Research Association, BERA. (2011). The role of research in teacher education: Reviewing the evidence.

Viju, M. K. (2015). The Study of Motivational Factors Affecting Teaching-Learning of English as Foreign Language. The Criterion: An International Journal in English, 5(3). https://doi.org/10.11648/j.ijl1.20150305.16

Wang, C., \& Pape, S. J. (2007). A probe into three Chinese boys' self-efficacy beliefs learning English as a second language. Journal of Research in Childhood Education, 21(4), 364-377. https://doi.org/10.1080/02568540709594601

Waseem, F., \& Jibeen, T. (2013). Anxiety amongst learners of English as a second language: An examination of motivational patterns in the Pakistani context. International Journal of Humanities and Social Science, 3(16), 174-184.

Wong, R. M. (2008). Motivation to Learn English and Age Differences: The Case of Chinese Immigrants.

Wu, W. C. V., \& Wu, P. H. N. (2008). Creating and authentic EFL learning environment to enhance student motivation to study English. Asian EFL Journal, 10(4), 211-226.

Yakushko, O., \& Chronister, K. M. (2005). Immigrant women and counseling: The invisible others. Journal of Counseling and Development, 83(Summer), 292-298. https://doi.org/10.1002/j.1556-6678.2005.tb00346.x

Yeung, A. S., Lau, S., \& Nie, Y. (2011). Primary and secondary students' motivation in learning English: Grade and gender differences. Contemporary Educational Psychology, 36(3), 246-256. https://doi.org/10.1016/j.cedpsych.2011.03.001

Zorza, J. (1996). Wife battering: A major cause of homelessness. Clearinghouse $R$.

Zusho, A., \& Pintrich, P. R. (2003). A process-oriented approach to culture: Theoretical and methodological issues in the study of culture and motivation. In F. Salili \& R. Hoosain (Eds.), Teaching, learning, and motivation in a multicultural context (pp. 33-65). Greenwich, CT: Information Age Publishing. 


\section{Appendix:}

\section{Questionnaire:}

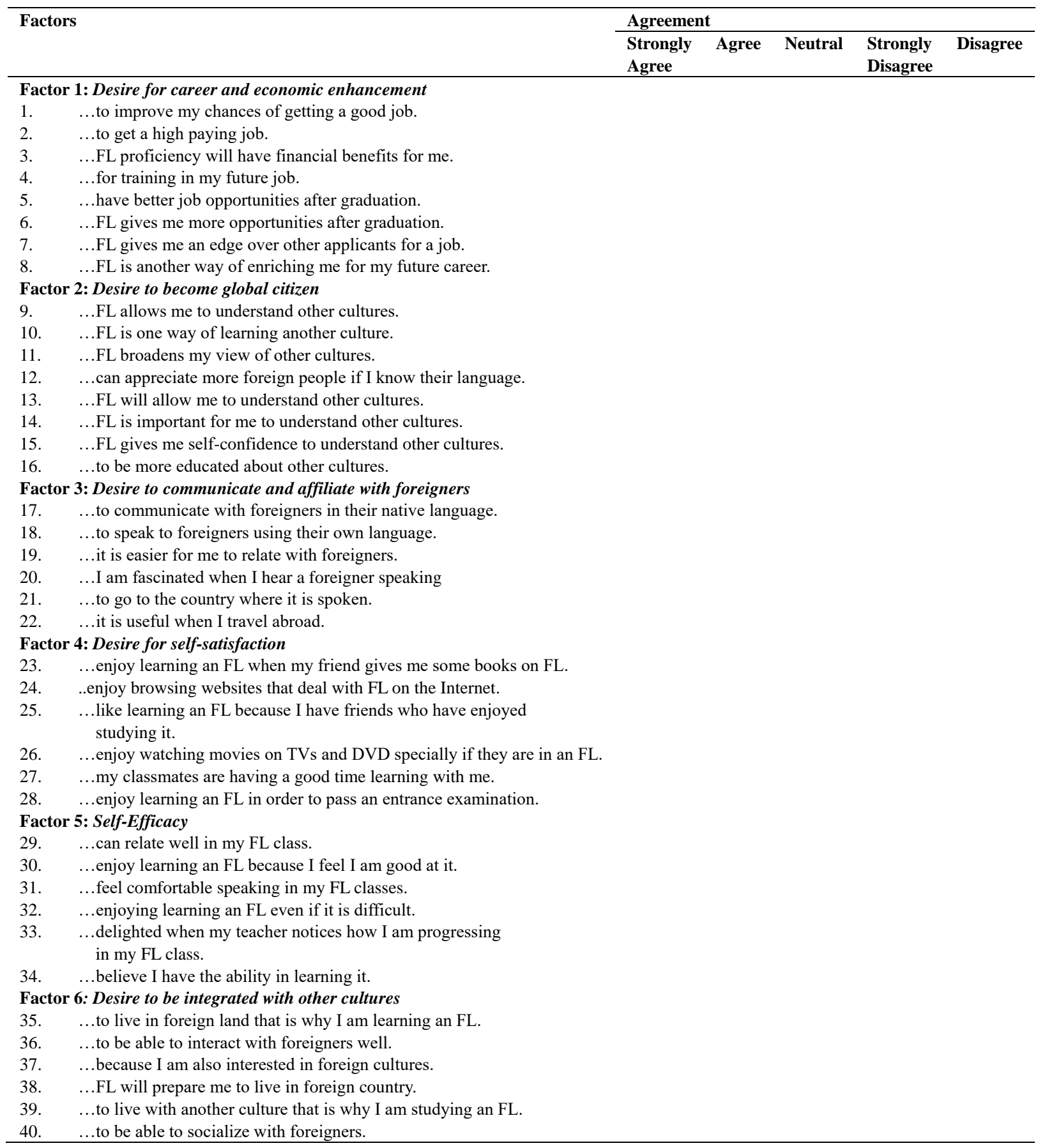

\section{Copyrights}

Copyright for this article is retained by the author(s), with first publication rights granted to the journal.

This is an open-access article distributed under the terms and conditions of the Creative Commons Attribution license (http://creativecommons.org/licenses/by/4.0/). 